\title{
Surveillance and Effect of Electronic Air Filtration on Surgical Site Infection in Operating Rooms of a Pediatric Surgery Department
}

\author{
${ }^{1}$ Maha M. Wahdan, ${ }^{1}$ Mohamed Y. El-Awady, ${ }^{2}$ Nagwa M. Abo EIMagd, ${ }^{2}$ Amany T. Abd \\ Elrahman, ${ }^{1}$ Isis M. Mossad, ${ }^{1}$ Ghada O. Wassif \\ ${ }^{1}$ Community, Environmental and Occupational Medicine Department, Faculty of Medicine, \\ Ain Shams University. ${ }^{2}$ Medical Microbiology and Immunology Department, Faculty of \\ Medicine, Ain Shams University, Cairo, Egypt. \\ Submission Date: 20-01-2021Ｒevision Date: 16-02-2021 Acceptance Date: 16-02-2021
}

\begin{abstract}
Background: Surgical site infections (SSI) lead to morbidity, extended hospitalization, and death. SSI surveillance is an important strategy to decrease SSI risk. Objectives: The study aimed to measure SSI incidence in pediatric surgeries, and to assess the effectiveness of electronic air filtration on surgical site infection rate in operating rooms of pediatric surgery department, Ain Shams university hospital. Method: An interventional study and a prospective SSI surveillance for 12 months (6 months before intervention) and (6 months after intervention) were done; where patients were tracked for 30 days after date of operation for the occurrence of SSI according to CDC Criteria, 2008 for SSI diagnosis. Data were collected through 3 worksheets for patient, surgery characteristics and telephone survey follow up. Intervention for improving air quality was performed by new electronic air decontamination unit beside the conventional ventilation system. Results: The overall incidence rate of SSIs was $24 \%$. SSIs rate and was significantly higher among control group than intervention group. Factors associated with SSIs were absence of chronic illness, discharge after surgery to ICU, contaminated surgical wound class, and long duration of surgery. Conclusion and recommendations: Intervention with electronic filtration device beside the conventional ventilation system is protective against SSIs as it improves air quality in operating rooms. Therefore, stress on the establishment of SSIs surveillance for tracking the incidence rate and addressing the possible controlling factors and more attention should be done to improve air quality in operating room to decrease the incidence of SSIs.
\end{abstract}

Keywords: Electronic Air Filtration, Surgical site infection, Surveillance

Corresponding author: Maha Magdy Wahdan Email: drmaha_wahdan@med.asu.edu.eg

\section{Introduction}

Surgical site infection (SSI) refers to an infection that occurs following surgery in part of the body where the surgery took place. SSIs are either superficial, deep space, or organ/space. ${ }^{1,2}$

Surgical site infection (SSI) is one of the most prevalent Healthcare associated
Infections. that estimated to account for $18.6 \%$ of inpatient HAI. ${ }^{3}$ In low- and middle-income countries, up to one third of patients who have undergone surgery are affected by SSI. Also, SSI represents the second most frequent form of HAI in highincome countries. ${ }^{4}$ SSI is considered a major

Oct. 
cause of morbidity, prolonged hospitalization, and death. It is associated with a $3 \%$ mortality rate. ${ }^{3}$ Surgical site infections result in extended length of stay at hospital, hospital readmissions, compromised quality of life and subsequent procedures. In addition to the detrimental effects on patients, SSIs are related to significant economic costs. ${ }^{5}$

Many factors associated with the potential occurrence of infection as patient-related (endogenous e.g., age, DM, gender, status of host defense against infection) and process/procedural-related (exogenous e.g., intraoperative contamination, Surgical team and hospital practice factors). ${ }^{4,6}$ Also, Operating theatre air that may contain microbial-laden dust, lint, skin squamous or respiratory droplets and length of time that tissues are exposed or the duration of the operation is also considered an important factor for development of SSI. The amount of microbial air in the operating room is directly proportional to the number of people in the room moving about. The longer the operation, the longer tissues are exposed to drying, trauma and to contamination by microorganisms. ${ }^{7,8}$

Efforts to reduce SSI should therefore be made. Infection prevention and control programs geared at environmental cleanliness are one of these initiatives. Operating rooms should also be kept under positive pressure in relation to corridors and adjacent areas. Positive pressure prohibits airflow from less clean areas into more clean areas. $^{9}$ Both hospital ventilation or air conditioning systems, including those in operating rooms, should have two filter beds in sequence, with $>30 \%$ efficiency of the first filter bed and $>90 \%$ efficiency of the second filter bed. A minimum of about 15 filtered air changes per hour are created by traditional operating room ventilation systems, of which three (20\%) must be fresh air. Air should be emitted at the ceiling and removed near the floor. ${ }^{10}$

Also, Surveillance of SSI with feedback to surgeons is necessary as it has been shown to be an essential aspect of SSI risk reduction strategies. ${ }^{11}$

In Egypt, previous studies were done where overall incidence rates of SSI that measured were $22.6 \%$ and $25.8 \%$ respectively in general surgical department in Tanta University and in Orthopedic Surgeries in Cairo University. ${ }^{12,13}$

According to the previous literature review, estimation of the surgical site infection problem in an Egyptian hospital and to study the effect of an interventional device on air quality in operating rooms on surgical site infection occurrence is necessary. Therefore, the current study aimed to measure the incidence of surgical site infection in pediatric surgery in the pediatric department and to assess the effect of electronic air filtration on the occurrence of surgical site infection in the pediatric surgery department operating rooms at Ain Shams University Hospital.

\section{Method}

Study Design: Interventional study was used for improving air quality by new electronic air decontamination unit then active, patientbased, prospective SSI surveillance for 12 months ( 6 months before intervention) and (6 months after intervention) was done to assess the effect of improving the air quality on SSIs rate; where patients underwent surgery were followed up for detecting the incidence of SSI according to CDC Guidelines, 2008 for diagnosis of SSI for 30 days after the date of surgery. ${ }^{14}$ The monitoring was conducted by committed and specially trained infection control staff. The study was carried out from June 2017 to August 2019. 
Study setting: operating rooms in pediatric surgery department, Ain Shams University Hospitals, they have 3 ORs; but the intervention was performed in only one operating room. The indoor air was conditioned but not heated. The operating theatre area was supplied by a ceilingmounted high quality particulate air (HEPA)-filtered laminar air flow with 15 air changes per hour (ACH), but an additional traditional air conditioning system was added in some rooms as the main HVAC system (heating, ventilation, and air conditioning). The HEPA filters are changed periodically and were last changed two months prior to sampling in the current study. As it is an old hospital, the operating room Conventional (mixing) ventilation system is used; the mixed ventilation works on the basis of the theory that the air supplied is very rapidly mixed with the current air in the room. The diffusion mechanism of the air supply is symmetrically positioned on the ceiling and the air flows uncontrollably and is subject to direction changes.

Study participants: The research included all children undergoing surgery during the time of observation (12 months from June 2017 to May 2018). Children were tracked for 1 month after the operation for the occurrence of surgical site infection by telephone. Exclusion criteria: Patients with minor one day surgeries, intra-operative implants, and discharge before 48 hours upon patient request with loss to follow up.

Data collection tools: data were collected by three worksheets: $1^{\text {st }}$ sheet for patient data, type of surgery, wound class, signs and symptoms of SSI and laboratory producers, $2^{\text {nd }}$ sheet for tracking patients in hospital, and 3rd sheet for tracking patients after discharge by Telephone survey for one month follow up. Data were collected before and after intervention.

The Egyptian Journal of Community Medicine

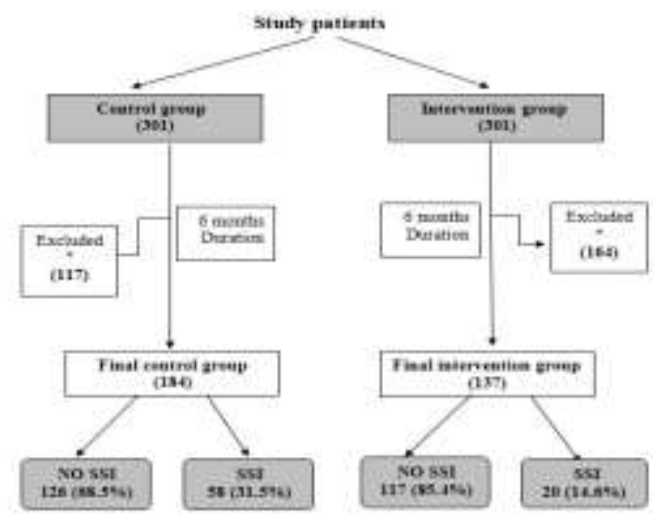

Figure (1): flow chart showing final recruited patient numbers

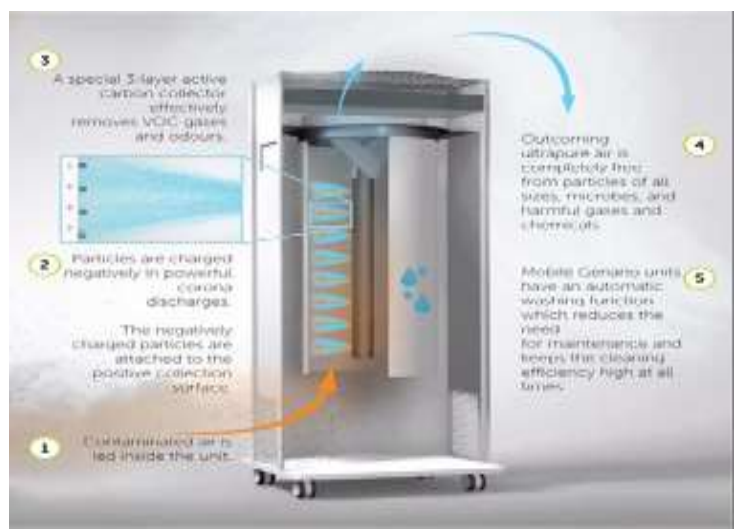

Figure (2): Electronic air decontamination unit (Genano ${ }$ 4500)

Intervention device: A new electronic air decontamination unit (Genano® 4500) was established by the Finnish hi-tech company Genano Ltd. to improve air quality. In one hour, the new Genano 4500 delivers up to $450 \mathrm{~m} 3$ of ultrapure air. Easy usage characterizes the machine. Genano 4500 uses Genano Technology®, which can collect all particle sizes down to particles of nano size $(1 \mathrm{~nm}=$ one millionth of a millionth of a particle), eliminate organisms, such as viruses and bacteria, and remove gases and odors as seen in Figure 2. The Genano 4500 was developed and assembled in Finland, in the EU. ${ }^{14}$

\section{Data management and analysis}

Data were revised, coded, entered on computer, and analyzed using SPSS
Vol. 39
No. 4
Oct. 
Table 1. Participants' and operations characteristics among intervention and control groups at operating rooms in pediatric surgery department, Ain Shams University Hospitals; in the period (June 2017 to August 2019).

\begin{tabular}{|c|c|c|c|}
\hline & $\begin{array}{c}\text { Control Group } \\
\text { (No Electronic Air } \\
\text { Filtration) }(\mathbf{N}=184) \\
\mathbf{N}(\%)\end{array}$ & $\begin{array}{c}\text { Intervention Group } \\
\text { (With Electronic Air } \\
\text { Filtration) (N=137) } \\
\text { N (\%) }\end{array}$ & $\underset{\text { value }}{\mathbf{P}_{-}}$ \\
\hline Age in months $(\text { mean } \pm S D)^{\dagger}$ & $61.05 \pm 51.42$ & $55.44 \pm 51.27$ & 0.334 \\
\hline \multicolumn{4}{|l|}{ Sex $\#$} \\
\hline Male & $99(53.8)$ & $81(59.1)$ & \multirow{2}{*}{0.559} \\
\hline Female & $85(46.2)$ & $56(40.9)$ & \\
\hline \multicolumn{4}{|l|}{ Chronic illness ${ }^{\#}$} \\
\hline Absent & $162(88.0)$ & $121(88.3)$ & \multirow{2}{*}{0.239} \\
\hline Present & $22(12.0)$ & $16(11.7)$ & \\
\hline \multicolumn{4}{|l|}{ Surgical Procedure } \\
\hline Hernia Repair & $20(10.9)$ & $5(3.6)$ & \multirow{6}{*}{$0.008 *$} \\
\hline GIT surgery & $117(63.6)$ & $92(67.2)$ & \\
\hline Hepato-biliary surgery & $9(4.9)$ & $6(4.4)$ & \\
\hline kidney-urinary tract surgery & $20(10.9)$ & $25(18.2)$ & \\
\hline Head \& Neck & $0(0.0)$ & $3(2.2)$ & \\
\hline General surgery & $18(9.8)$ & $6(4.4)$ & \\
\hline \multicolumn{4}{|l|}{ Discharge room after surgery } \\
\hline Intermediate care & $148(80.4)$ & $81(59.1)$ & \multirow{2}{*}{$0.000 * *$} \\
\hline Intensive care & $36(19.6)$ & $56(40.9)$ & \\
\hline \multicolumn{4}{|l|}{ Indication of surgery } \\
\hline Elective & $97(52.7)$ & $71(51.8)$ & \multirow{2}{*}{0.874} \\
\hline Emergency & $87(47.3)$ & $66(48.2)$ & \\
\hline \multicolumn{4}{|l|}{ Wound class } \\
\hline Clean & $62(33.7)$ & $39(28.5)$ & \multirow{2}{*}{0.318} \\
\hline Contaminated/Dirty & $122(66.3)$ & $98(71.5)$ & \\
\hline $\begin{array}{l}\text { Duration of surgery (Hours) } \\
(\text { mean } \pm S D)^{+}\end{array}$ & $2.70 \pm 1.17$ & $2.99 \pm 1.05$ & $0.025^{*}$ \\
\hline
\end{tabular}

( + Independent t test; (\#) chi square test; $(*)$ statistically significant at $P<0.05$ package version number 20. Quantitative data were presented as mean, standard deviation (SD) and range values. For the comparison of quantitative variables between groups, the independent $\mathrm{t}$ - test was used. Qualitative data were summarized as frequencies (n) and percentage $(\%)$. Chi square and fisher exact test were used to test association between qualitative variables. P-value $\leq$ 0.05 was considered significant. To evaluate the predictors of the occurrence of SSIs, multivariable logistic regression analysis was conducted, where variables found to be significant in bivariate analysis were included.

The incidence of SSI was computed as follows: (Number of patients who developed SSI among patients who had surgery and complied with inclusion criteria / Number of patients who had surgery and met the inclusion criteria) * 100.

\section{Ethical considerations}

Enrollment of participants in study was started after taking Ethical committee board approval in Faculty of medicine, Ain Shams University (reference no. 
000017585) on September $20^{\text {th }}$, 2016; administrative

Table 2. Surgical site infection among control group \& intervention group at operating rooms in pediatric surgery department, Ain Shams University Hospitals; in the period (June 2017 to August 2019).

\begin{tabular}{|c|c|c|c|c|}
\hline & $\begin{array}{c}\text { Control Group } \\
\text { (No Electronic Air } \\
\text { Filtration) }(\mathbf{N}=184) \\
\mathbf{N}(\%)\end{array}$ & $\begin{array}{c}\text { Intervention Group } \\
\text { (Electronic Air } \\
\text { Filtration) }(\mathbf{N}=137) \\
\mathbf{N}(\%)\end{array}$ & $\begin{array}{c}\text { RR } \\
(95 \% \mathrm{CI})\end{array}$ & P-value \\
\hline \multicolumn{5}{|l|}{ SSI ${ }^{\#}$} \\
\hline $\begin{array}{l}\text { Absent } \\
\text { Present }\end{array}$ & $\begin{array}{r}126(68.5) \\
58(31.5)\end{array}$ & $\begin{array}{r}117(85.4) \\
20(14.6)\end{array}$ & $0.37(0.21-0.66)$ & $<0.001 *$ \\
\hline
\end{tabular}

$\left({ }^{\#}\right)$ Chi square test; $(*)$ statistically significant at $P<0.01$

approval from hospital director of Ain Shams University hospitals. Written informed consent was waived as data were collected through data collection sheets only and there was no invasive procedure done to participant; therefore, verbal informed consent was taken from each participant's caregiver.

\section{Results}

The final figures of patients in intervention and control groups recruited (137 vs. 184 respectively) as seen in Figure 1. There is no significant difference noted between Control group (No Electronic Filtration) versus Intervention group (With Electronic Filtration) as regards Age, Sex, and presence of chronic diseases, i.e., matched groups. However, in terms of surgical procedure, discharge room after surgery and length of surgery (hours), there is a statistically significant difference between the two groups; where a slightly higher proportion of the intervention group was discharged to the intensive care unit $40.9 \%$ compared to $19.6 \%$ of the control group, and even the intervention group had a longer duration of surgery (hours) compared to the control group $(2.99 \pm 1.05$ vs. $2.70 \pm 1.17)$. However, there is insignificant difference between Control group and Intervention group regarding Indication of surgery or Wound Class as shown in Table 1.
Table 2 indicates that there is a highly significant difference in surgical site infection between the control group and the intervention group, where SSI is notably higher in the control group than in the intervention group (31.5\% vs. $14.6 \%)$ $(\mathrm{RR}=0.371 ; 95 \% \mathrm{CI}=0.211-0.655)$.

Table 3 shows that $(91 \%)$ of SSIs were discovered in the hospital after surgery while patients are still hospitalized, (76.9\%) of SSIs were superficial, and $(79.5 \%)$ of SSIs were presented by Pus discharged from the wound. Most SSIs (70.5\%) were swapped; where the commonest cultured organism was E coli (41.8\%) followed by MRSA (14.5\%). Most patients with SSIs (98.7\%) received antibiotics; the most used antibiotic was Flagyl (40.3\%) followed by Amikin $(32.5 \%)$. SSIs were diagnosed after a mean period of $2.99 \pm 1.69$ days.

Regarding factors affecting SSI occurrence, there is insignificant difference between patients with and without SSIs regarding Age and Sex; However, chronic illness was significantly higher in patients without SSI than patients with SSIs; (RR = 0.332; $95 \% \mathrm{CI}=0.114-0.968)$. Also, significant higher percentage of patients with SSI were discharged after surgery to the intensive care room as compared to patients without SSIs $(\mathrm{RR}=2.122$; $95 \% \mathrm{CI}=1.240-3.631)$. In addition to that, SSI patients had a significantly higher

Oct.

2021 
percentage of contaminated/Dirty wound

than

patients

Table 3. Characteristics of patients with surgical site infection at operating rooms in pediatric surgery department, Ain Shams University Hospitals; in the period (June 2017 to August 2019) $(\mathbf{N}=78)$.

\begin{tabular}{|c|c|c|}
\hline Variables & No. & $\%$ \\
\hline \multicolumn{3}{|l|}{ Place of SSI Diagnosis } \\
\hline Directly after surgery (Hospital) & 71 & 91.0 \\
\hline Clinic & 7 & 9.0 \\
\hline \multicolumn{3}{|l|}{ SSI Type } \\
\hline Superficial & 60 & 76.9 \\
\hline Deep/Organ & 18 & 23.1 \\
\hline \multicolumn{3}{|l|}{ SSI Presentation } \\
\hline Redness and swelling around wound & 14 & 17.9 \\
\hline Pus discharge & 62 & 79.5 \\
\hline Pain or tenderness in wound & 1 & 1.3 \\
\hline Chills and fever above 38 & 1 & 1.3 \\
\hline \multicolumn{3}{|l|}{ Swab taken? } \\
\hline Yes & 55 & 70.5 \\
\hline No & 23 & 29.5 \\
\hline \multicolumn{3}{|l|}{ Organism type $(n=55)$} \\
\hline Klebseilla & 7 & 12.7 \\
\hline Staph coagulase negative & 5 & 9.1 \\
\hline Ecoli & 23 & 41.8 \\
\hline MRSA & 8 & 14.5 \\
\hline No growth & 5 & 9.1 \\
\hline Acinetobcter species & 7 & 12.7 \\
\hline \multicolumn{3}{|l|}{ Antibiotic received? } \\
\hline Yes & 77 & 98.7 \\
\hline No & 1 & 1.3 \\
\hline \multicolumn{3}{|l|}{ Type of antibiotic $(n=77)$} \\
\hline Augmantin & 17 & 22.1 \\
\hline Amakin & 25 & 32.5 \\
\hline Bavetracin spray & 4 & 5.2 \\
\hline Flagyl & 31 & 40.3 \\
\hline
\end{tabular}

\begin{tabular}{ll}
\hline Timing of Diagnosis of SSI (Days) $($ mean $\pm S D)$ & \multicolumn{1}{c}{$2.99 \pm 1.69$} \\
\hline without SSI (RR= 1.896; 95\% CI=1.041- & $((\mathrm{RR}=0.212 ; 95 \% \mathrm{CI}=0.113-0.397), 0.993$ \\
3.451). In addition, the length of surgery & $(0.988-0.999), \quad 0.289 \quad(0.093-0.894)$ \\
was higher in SSI patients relative to non- & $\begin{array}{l}\text { respectively) respectively. While Discharge } \\
\text { SSI patients. On contrast to that, the }\end{array}$ after surgery to the ICU is a Risk factor for \\
disparity between patients with and & SSI (RR = 2.391; 95\%CI = 1.259-4.540) as \\
without SSIs in terms of surgical technique & presented in Table 5.
\end{tabular}
and indication of surgery was insignificant as stated in Table 4.

Multivariable logistic regression analysis showed that Intervention method, Age in months and Chronic illness are significant protective independent predictors of SSIs

\section{Discussion}

Regarding the overall incidence of SSIs, A prospective surveillance was done on 321 pediatric patients underwent elective and emergency general surgical operations in 
Table 4. Surgical site infection in relation to patients' and operation characteristics at operating rooms in pediatric surgery department, Ain Shams University Hospitals; in the period (June 2017 to August 2019).

\begin{tabular}{|c|c|c|c|c|}
\hline & $\begin{array}{l}\text { SSI Absent } \\
(\mathrm{N}=\mathbf{2 4 3})\end{array}$ & $\begin{array}{c}\text { SSI Present } \\
(\mathrm{N}=78)\end{array}$ & $\begin{array}{l}\text { Crude RR } \\
(95 \% \text { CI })\end{array}$ & P-value \\
\hline Age in months $(\text { mean } \pm S D)^{\dagger}$ & $61.07 \pm 53.63$ & $51.14 \pm 42.92$ & -- & 0.098 \\
\hline \multicolumn{5}{|l|}{$\operatorname{Sex}^{\#}$} \\
\hline Male $(n=180)$ & $138(76.7)$ & $42(23.7)$ & 1 & \multirow{2}{*}{0.649} \\
\hline Female $(n=141)$ & $105(74.5)$ & $36(25.5)$ & $1.13(0.68-1.88)$ & \\
\hline \multicolumn{5}{|l|}{ Chronic illness ${ }^{\#}$} \\
\hline Absent $(n=283)$ & 209 (73.9) & $74(26.1)$ & 1 & \multirow{2}{*}{$0.035^{*}$} \\
\hline Present $(n=38)$ & $34(89.5)$ & $4(10.5)$ & $0.33(0.11-0.97)$ & \\
\hline \multicolumn{5}{|l|}{ Surgical Procedure } \\
\hline Hernia Repair $(n=25)$ & $18(72.0)$ & $7(28.0)$ & \multirow{7}{*}{--- } & \multirow{7}{*}{0.367} \\
\hline GIT surgery $(n=209)$ & $151(72.2)$ & $58(27.8)$ & & \\
\hline Hepato-biliary surgery $(n=15)$ & $13(86.7)$ & $2(13.3)$ & & \\
\hline kidney-urinary tract surgery & & & & \\
\hline$(\mathrm{n}=45)$ & $38(84.4)$ & $7(15.6)$ & & \\
\hline Head \& Neck $(n=3)$ & $3(100.0)$ & $0(0.0)$ & & \\
\hline General surgery $(n=24)$ & $20(83.3)$ & $4(16.7)$ & & \\
\hline \multicolumn{5}{|l|}{ Discharge room after surgery } \\
\hline Intermediate care $(n=229)$ & $183(79.9)$ & $46(20.1)$ & 1 & \multirow{2}{*}{$0.006 * *$} \\
\hline Intensive care $(n=92)$ & $60(65.2)$ & $32(34.8)$ & $2.12(1.24-3.63)$ & \\
\hline \multicolumn{5}{|l|}{ Indication of surgery } \\
\hline Elective $(n=168)$ & $131(78.0)$ & $37(22.0)$ & 1 & \multirow{2}{*}{0.319} \\
\hline Emergency $(n=153)$ & $112(73.2)$ & $41(26.8)$ & $1.30(0.78-2.16)$ & \\
\hline \multicolumn{5}{|l|}{ Wound class } \\
\hline Clean $(n=101)$ & $84(83.2)$ & $17(16.8)$ & 1 & \multirow{2}{*}{$0.035^{*}$} \\
\hline Contaminated/Dirty $(n=220)$ & $159(72.3)$ & $61(27.7)$ & $1.90(1.04-3.45)$ & \\
\hline $\begin{array}{l}\text { Duration of surgery (Hours) } \\
(\text { mean } \pm S D)^{\dagger}\end{array}$ & $2.74 \pm 1.12$ & $3.06 \pm 1.11$ & --- & $0.029 *$ \\
\hline
\end{tabular}

(†) Independent t test; (\#) chi square test; $(*)$ statistically significant at $P<0.05$

pediatric department at Ain Shams from $21 \%$ to $26 \%)^{22,23,24,25}$ But, it was University, where the incidence rate of SSI lower compared to other studies done in during the surveillance period among all studied cases was 78/321 (24\%). Compared with those reported in literature previously conducted studies in different countries, this rate is considered high, with the rate of postoperative wound infection in children ranging significantly from 1.7 to $30 \%{ }^{7}, 15,18,19$ In Egypt, previous studies were done in hospitals and reported rates vary from $9.2 \%$ to $12 \% .^{20,21}$

However, the current study rate of SSI was close to the rates in previous studies done in India, Nigeria, and Tanzania (ranging India and Ethiopia $(33.5 \%$ \& $75 \%$ respectively). ${ }^{26,27}$

Regarding comparison between the characteristics of control and intervention groups; the current study participants' characteristics in both groups were matched and did not show any significant difference regarding Age, Sex and Presence of any chronic illness, and that allowed fair comparison.

Also, there was insignificant difference between both groups concerning Indication 
of surgery (Elective vs. Emergency) and

Wound Class (clean vs. contaminated). On

Table 5. Binary Logistic Regression Displaying Independent Predictors of Surgical Site infection at operating rooms in pediatric surgery department, Ain Shams University Hospitals; in the period (June 2017 to August 2019).

\begin{tabular}{|c|c|c|c|c|c|c|c|}
\hline \multirow{2}{*}{ Variables } & \multirow{2}{*}{ B } & \multirow{2}{*}{ S.E. } & \multirow{2}{*}{ Wald } & \multirow{2}{*}{ Sig. } & \multirow{2}{*}{ Adjusted RR } & \multicolumn{2}{|c|}{ 95\% C.I. for RR } \\
\hline & & & & & & Lower & Upper \\
\hline Intervention & -1.553 & .321 & 23.435 & $.000^{*}$ & .212 & .113 & .397 \\
\hline Age in months & -.007 & .003 & 5.199 & $.023 *$ & .993 & .988 & .999 \\
\hline Sex & -.167 & .259 & .416 & .519 & .846 & .509 & 1.406 \\
\hline Chronic illness & -1.242 & .576 & 4.642 & $.031 *$ & .289 & .093 & .894 \\
\hline $\begin{array}{l}\text { Discharge } \\
\text { surgery }\end{array}$ & .872 & .327 & 7.094 & $.008 *$ & 2.391 & 1.259 & 4.540 \\
\hline Wound class & .181 & .270 & .448 & .503 & 1.198 & .706 & 2.034 \\
\hline Duration of operation & -.103 & .088 & 1.394 & .238 & .902 & .760 & 1.071 \\
\hline
\end{tabular}

(*) Statistically significant at $P<0.05$

the other hand, there was a significant difference between the control and intervention groups as regards surgical procedure, discharge room after surgery. It was found that $49.9 \%$ were admitted to intensive care in intervention group compared to $19.6 \%$ in control group, and a significantly higher percentage of the intervention group versus the control group were discharged to the intensive care unit (40.9\% vs $19.6 \%$ ). In addition, the intervention group had longer duration of surgery in hours compared to the control group $(2.99 \pm 1.05$ vs $2.70 \pm 1.17)$. However, there was insignificant difference between both groups as regards Indication of surgery or Wound Class.

Regarding the SSI rate in both groups, it was noted that there was a very significant difference in surgical site infection between the control and intervention groups; where SSI in control group was significantly higher than intervention group respectively $(31.5 \%$ vs. $14.6 \%)$ $(\mathrm{RR}=0.371 ; 95 \%$ CI $(0.211-0.655)$. It would be expected to have much lower incidence of SSI in the intervention group if the ventilation system was well controlled as the mixed ventilation in the intervention OR affects air quality adversely. These results are supported by a

previous study conducted with the same intervention in the same study settings, where assessment of air quality in operating rooms at pediatric surgical hospital was done through measuring the amount of Particulate matter and bacterial Sampling, where there was highly significant decrease in Particulate matter and bacteria as E. coli, klebsiella, pseudomonas between before and after intervention. $^{14}$

As regards SSIs risk factors; there was insignificant difference between patients with and without SSIs regarding Age, this finding is similar to a study done in Estonia investigating the occurrence and risk factors of surgical wound infection in children ${ }^{28}$ However, contrary to other studies conducted in university hospitals that showed that age $<1$ month and longer period of surgery were independently correlated with hospitalized SSI in children, other studies documented a higher incidence of SSI in infants compared to newborns and other age groups. ${ }^{29,30}$

There was insignificant difference between patients with and without SSIs as regards gender in our current study. Other studies findings were similar to this finding; ${ }^{28,} 31$ unlike Ansari et al., 2015 study in which

Oct. 
SSI was higher in males (70\%) compared to females (30\%). ${ }^{32}$

Chronic illness was significantly associated with patients without SSI; (RR= $0.332 ; 95 \% \mathrm{CI}=0.114-0.968)$ which is different from what found by Ashisha et al., 2014 study where SSI more common with chronic illness but the finding in our study may be due to the strict preparation and tight control and follow up of those chronic patient as they are considered high risk. $^{33}$

In the current study, there was no significant association between SSI and indication of surgery and wound class, which disagreed with previous study conducted in teaching hospitals in India and reported that the risk of wound infection in emergency operations is higher. $^{15}$

SSIs were significantly associated with prolonged surgery lasting three hours or more in current work. This result is like that observed in other studies, $15,30,35,36$ where a desirable cutoff value (120-200 minutes) was suggested. Results obtained in 2017 from Shibahashi and his colleagues showed that an optimal cutoff value is a shorter operating time of 98 minutes. ${ }^{34}$

But, in another study by Khairy and his colleagues, 2011; there was insignificant difference regarding the occurrence of postoperative SSI in patients with prolonged surgery than those who had shorter surgery time. ${ }^{37}$

There was an insignificant difference in surgical procedures between patients with and without SSIs. Our findings are in line with those of Bhattacharyya et al. where SSI more often occurs in patients who have undergone gastrointestinal tract or abdominal cavity surgery, which was due to gut material contamination of the wound. $^{28,30}$
The wound classification system was created to have universal utility in identifying procedures with an inherently higher risk of postoperative infection; therefore, SSI patients in current study had a significantly higher percentage of contaminated/Dirty wound than patients without SSI $(\mathrm{RR}=1.896 ; 95 \% \mathrm{CI}=1.041$ 3.451). In combination with other variables in a binary logistic regression model, the wound type displayed negligible results. This result is close to what was observed in previous studies in which there was an increased risk for deep SSIs in polluted and dirty situations. ${ }^{38,39}$

As regards SSIs bacteriology; (70.5\%) of SSIs were swabbed and results of bacteriological culture showed that gram negative pathogens were common than gram positive where $\mathrm{E}$ coli was the commonest organism cultured $(41.8 \%)$ then MRSA (14.5\%), $98.7 \%$ received antibiotics mainly Flagyl (40.3\%) and Amakin (32.5\%). The rest was either not swabbed due to responding to regular antibiotic regimen or due to under reporting from data collection team. Similar findings were documented in earlier studies in which the most common gram-negative bacilli isolated were Escherichia coli, Klebsiella species; while Staphylococcus aureus and coagulasenegative staphylococci were the most isolated gram-positive organisms. ${ }^{17,19,28,31}$ While different results were reported by Ansari et al., 2015 study as Staphylococcus aureus (25\%) was the commonest gram-positive cocci isolated from SSI cases. ${ }^{32,16}$

\section{Conclusion and Recommendations}

The overall SSI incidence rate was $24 \%$ lower than that recorded in some developing countries, and higher than that reported in developed countries. The risk

Oct.

2021 
factors for SSIs were poor air quality, absence of chronic disease as there is rigorous preparation, discharge after surgery to ICU, surgical wound class either contaminated or dirty class, and long duration of surgery. Thus, it is important to develop routine monitoring of nosocomial infections with periodic evaluation to track incidence and risk factors. On the other hand, apart from the traditional ventilation system, intervention with electronic filtration systems is protective against SSIs as it enhances air quality by decreasing the particulate matter and bacteria in the air.

Study Limitations: The sampling of air and surgeries were done in the presence of mixed ventilation in the operation rooms, so that air quality may be affected adversely during the intervention phase. Also, only $70.5 \%$ of SSIs were swabbed, the rest was either not swabbed due to responding to regular antibiotic regimen or due to under reporting from data collection team.

\section{Declarations}

Consent for publication: Consent to publish was not applicable.

Availability of data and material: The datasets generated and analysed during the current study are available from the corresponding author on request.

Competing interests: The authors state that they have no competing interests.

Funding: No significant financial support for this work that could have influenced its outcome.

Authors' contributions: MI, AM: Conceived and designed the study. MI, AA, AN, AM: Data collection and facilitations in the field. MI, WG, WM: Analyzed data and Discussion writing. MI, WG, WM, AA, AN, AM: Drafted and Critical revision of the manuscript. All authors read and approved the final version of the manuscript.

\section{Acknowledgment:}

Authors would like to express their great appreciation to patients' caregivers who generously shared their time and agreed to participate in this study.

\section{References}

1. Centers for Disease Control and Prevention (CDC). CDC Guideline for the Prevention of Surgical Site Infection. JAMA Surg. 2017 Aug 1; 152(8):784-91. DOI: 10.1001/jamasurg.2017.0904. Available at: https://www.ncbi.nlm.nih.gov/pubmed/284675 $\underline{26}$

2. Pham JC, Melinda J, Ashton MJ, Kimata C, Lin DM and Nakamoto BK. Surgical site infection: comparing surgeon versus patient self-report. J Surg Res. 2016 May 1; 202(1):95-102.

DOI: 10.1016/j.jss.2015.12.039.

3. Centers for Disease Control and Prevention (CDC). Guidelines for prevention of surgical site, Surgical Site Infection Event, in Procedure-associated Module SSI. 2016; (1): 9-31. Available at: https://www.cdc.gov/nhsn/pdfs/pscmanual/9ps cssicurrent.pdf

4. World Health Organization (WHO). Global guidelines for the prevention of surgical site infection. 2016. Available at: http://www.who.int/gpsc/ssi-preventionguidelines/en/

5. Anderson DJ, Podgorny K, Berríos-Torres SI, Bratzler DW, Dellinger EP, Greene L, et al. Strategies to Prevent Surgical Site Infections in Acute Care Hospitals. Infect Control Hosp Epidemiol. 2014; 35(6): 605-27. DOI:10.1086/676022.

6. Ramos A, Asensio A, Muñez E, TorreCisneros J, Montejo M, Aguado JM, et al. Incision surgical site infection in kidney transplantation. Urology. 2008; 72(1):119-23. DOI: 10.1016/j.urology.2007.11.030. 
7. Sangrasi AK, Leghari AA, Memon A, Talpur AK, Qureshi GA, Memon JM. Surgical site infection rate and associated risk factors in elective general surgery at a public sector medical university in Pakistan. Int Wound J. 2008; 5 (1):74-8. DOI:10.1111/j.1742-481X.2007.00365. x.

8. El Awady MY, El Rahman AT, Al Bagoury LS, Mossad IM. Air quality in Ain Shams University Surgery Hospital. J Egypt Soc Parasitol. 2014 Dec; 44(3):749-59. DOI:10.12816/0007878

9. World Health Organization (WHO). Prevention of hospital-acquired infections. A practical guide, 2nd edition. 2002. Retrieved November 9, 2018. Available at: http://www. WHO/CDS/CSR/EPH/2002.12

10. Nichols RL. The operating room (Chapter 22). In J. V. Bennett \& P. S. Brachman (Eds.), Hospital Infections. 3rd ed. Boston: Little, Brown and Co. 1992; 461-73.

11. Brandt C. Reduction of surgical site infection rates associated with active surveillance. Infect Control Hosp Epidemiol. 2006; 27(12): 1347-51. DOI:10.1086/509843

12. Afifi IK, Labah EA and Ayad KM. Surgical site infections after elective general surgery Tanta university hospital: rate, risk factors and microbiological profile Egyptian. J. Med. Microbiol. 2009; 18 (2): 61-72.

13. Abdel-Haleim KM, Ibraheim ZA and ElTahlawy EM. Surgical site infections and associated risk factors in Egyptian orthopedic patients. Am. J. Sci. 2010; 6(7): 272-80.

14. Centers for Disease Control and Prevention (CDC). CDC/NHSN Surveillance definition of healthcare-associated infection and criteria for specific types of infections in the acute care setting. 2008. Available at: http://www.cdc.gov/cdc\%20clinical\%20criteri a\%20for\%20HAI.pdf

15. Uludag Ö, Rieu P, Niessen M, Voss A. Incidence of surgical site infections in pediatric patients: a 3-month prospective study in an academic pediatric surgical unit. Pediatr Surg Int. 2000; 16(5-6):417-20. DOI:10.1007/s003830000389
16. Sievert DM, Ricks P, Edwards JR, Schneider A, Patel J, Srinivasan A, et al. Antimicrobial resistant pathogens associated with health care associated infections: summary of data reported to the National Healthcare Safety Network at the Centers for Disease Control and Prevention. Infect Control Hosp Epidemiol. 2013; 34(1): 1-14. DOI: 10.1086/668770.

17. Hafez S, Saied T, Hasan E, Elnawasany M, Ahmad E, Lloyd L, et al. Incidence and modifiable risk factors of surveillance of surgical site infections in Egypt: A prospective study. Am J Infect Control. 2012; 40(5): 42630. DOI: 10.1016/j.ajic.2011.07.001.

18. Elbur AI, Sayed A, Elsayed A, Abdelrahman ME. Prevalence and predictors of wound infection in elective clean and clean/contaminated surgery in Khartoum Teaching Hospital, Sudan. Int J Infect Control. 2012; $\quad 8(4): 1-10 . \quad$ DOI: 10.3396/ijic.v8i4.036.12

19. Reddy BR, Vani J, Gade PS. Trends in surgical site infections in general surgery at a tertiary hospital. J Med Allied Sci. 2012; 2(1): 19-22

20. Wassef MA, Hussein A, Abdul Rahman EM, El-Sherif RH. A prospective surveillance of surgical site infections: Study for efficacy of preoperative antibiotic prophylaxis. Afr $\mathbf{J}$ Microbiol Res. 2008; 6(12):3072-8. DOI: 10.5897/AJMR12.377

21. Abduo EM, El-Kholy A, Abdou S, Hafez $\mathrm{S}$, Omar N, Talaat M. Incidence and microbial etiology of surgical site infections at select hospitals in Egypt". Am. J. Infect. Control. 2016; 44(6): S52-S53. DOI: 10.1016/j.ajic.2016.04.049

22. Mahesh CB, Shivakumar S, Suresh BS, Chidanand SP. A Prospective study of surgical site infections in a teaching hospital. J Clin Diagn Res. 2010; 4:3114-9. DOI: http://dx.doi.org/10.18203/2349-

2902.isj20164448 
23. Mawalla B, Mshana SE, Chalya PL, Imirzalioglu C, Mahalu W. Predictors of surgical site infections among patients undergoing major surgery at Bugando Medical Centre in Northwestern Tanzania. BMC Surg. 2011 Aug; 11-21. DOI: 10.1186/1471-248211-21.

24. Nwankwo EO, Ibeh IN, Enabulele O. Incidence and risk factors of surgical site infection in a tertiary health institution in Kano, Northwestern Nigeria. Int $\mathrm{J}$ Infect Control. 2012; 8(4):8-13. DOI: https://doi.org/10.3396/ijic.v8i4.10573.

25. Kikkeri N, Setty $H$, Shimoga $M$, Halumatthigatta D, Giriyaiah S, Ramanagaram $\mathrm{N}$, et al. A study on surgical site infections (SSI) and associated factors in a government tertiary care teaching hospital in Mysore, Karnataka. Int J Med Public Health. 2014; 4(2):171-5. DOI: 10.4103/2230-8598.133126.

26. Amutha B, Viswanathan T, Science I, Association C. A retrospective study on the pattern of pathogens isolated from surgical site wound infection in tertiary care hospital in Coimbatore, India. Int Res J Med Sci. 2014; 2(10):1-6.

27. Mengesha RE, Kasa BG-S, Saravanan M, Berhe DF, Wasihun AG. Aerobic bacteria in post-surgical wound infections and pattern of their antimicrobial susceptibility in Ayder teaching and referral hospital, Mekelle, Ethiopia. BMC Res Notes. 2014; 7(575):4-9. DOI: $10.1186 / 1756-0500-7-575$.

28. Varik K, Kirsimagi U, Värimäe E., Eller M., Lõivukene R., Kübarsepp V. Incidence and risk factors of surgical wound infection in children: a prospective study. Tartu University, Estonia. Scand J Surg. 2010; (99):162-66. DOI:

https://doi.org/10.1177/145749691009900311

29. Allpress AL, Rosenthal GL, Goodrich KM, Lupinetti FM, Zerr DM. Risk factors for surgical site infections after pediatric cardiovascular surgery. Pediatr Infect Dis J. 2004; 23(3):231-4. DOI: https://doi.org/10.1016/j.athoracsur.2009.08.08 1
30. Bhattacharyya N and Kosloske AM. Postoperative wound infection in pediatric surgical patients: a study of 676 infants and children. J Pediatr Surg. 1990; 25:125-9.

31. Ansari SK, Randhawa VS, Mishra and Choudhury SR. Microbial etiology and risk factor analysis of pediatric surgical site infections in a tertiary care hospital. Int $\mathbf{J}$ Curr Microbiol Appl Sci. 2015; 4 (4): 890-8. Available at: https://pdfs.semanticscholar.org/0ce0/c66f915 4e146abd5018aa50ae905e78692d7.pdf

32. Ashish P, Erika AS, Shailendra S, Vijay KM, Harshada S, Cecilia SL. Incidence and factors associated with surgical site infections in a teaching hospital in Ujjain, India. Am $\mathbf{J}$ Infect Control. 2014; 42: 11-5. DOI: 10.1016/j.ajic.2013.06.013.

33. Togo A, Coulibaly Y, Dembélé BT, Togo B, Keita M, Kanté L, et al. Risk factors for Surgical Site Infections in children at the teaching hospital Gabriel Toure, Bamako. J Hosp Infect. 2011; 79:371-2.

34. Shibahashi K, Hoda H, Takasu Y, Hanakawa K, Ide T, Hamabe Y. Cranioplasty outcomes and analysis of the factors influencing surgical site infection: a retrospective review of more than 10 years of institutional experience. World Neurosurgery. 2017; 101: 20-5.

35. Legesse Laloto T, Hiko Gemeda D, Abdella SH. Incidence and predictors of surgical site infection in Ethiopia: prospective cohort. BMC Infect Dis. 2017; 17(1):119. DOI: 10.1186/s12879-016-2167-x.

36. Yesuf BY. Prospective evaluation of antimicrobial prophylaxis and other risk factors for surgical site infection at surgical ward. Clinc Pharmaco Bipharm. 2014; 3(2). DOI: 10.4172/2167-065X.S1.007

37. Khairy G, Kambal A, Al-Dohayan A. Surgical site infection in a teaching hospital: a prospective study. Journal of Taibah University Medical Sciences. 2011; 6(2): 11420. DOI: https://doi.org/10.1016/S16583612(11)70172-X

Oct. 
38. Mioton LM, Jordan SW, Hanwright PJ, Bilimoria KY, Kim JY. The Relationship between preoperative wound classification and postoperative infection: a multi-institutional analysis of 15,289 patients. Archives of Plastic Surgery. 2013; 40(5): 522-9. DOI: 10.5999/aps.2013.40.5.522
39. Ortega G, Rhee DS, Papandria DJ, Yang J, Ibrahim AM, Shore AD, et al. An evaluation of surgical site infections by wound classification system using the ACS-NSQIP. J Surg Res. 2012; 174(1):33-8. DOI: 10.1016/j.jss.2011.05. 